\title{
The dynamics of the mesosphere and lower thermosphere: a brief review
}

\author{
Robert A Vincent
}

\begin{abstract}
The dynamics of the mesosphere-lower thermosphere (MLT) $(60$ to $110 \mathrm{~km})$ is dominated by waves and their effects. The basic structure of the MLT is determined by momentum deposition by small-scale gravity waves, which drives a summer-to-winter pole circulation at the mesopause. Atmospheric tides are also an important component of the dynamics of the MLT. Observations from extended ground-based networks, satellites as well as numerical modelling show that non-migrating tidal modes in the MLT are more important than previously thought, with evidence for directly coupling into the thermosphere/ionosphere. Major disturbances lower in the atmosphere, such as wintertime sudden stratospheric warmings, temporarily disrupt the circulation pattern and thermal structure of the MLT. In the equatorial mesosphere, gravity wave driving leads to oscillations in the zonal wind on semiannual time scales, although variability on quasi-biennial time scales is also apparent. Planetary-scale waves such as the quasi-two-day wave temporarily dominate the dynamics of the summertime MLT, especially in the southern hemisphere. Impacts may include short-term changes to the thermal structure and physics of the high-latitude MLT. Here, we briefly review the dynamics of the MLT, with a particular emphasis on developments in the past decade.
\end{abstract}

Keywords: Atmospheric tides; Gravity waves; Planetary waves; Middle atmosphere; Mesosphere; Lower thermosphere; Wave coupling

\section{Review}

\section{Introduction}

The mesosphere-lower thermosphere (MLT) is defined as the region of the atmosphere between about 60 and 110 $\mathrm{km}$ in altitude. It constitutes the upper part of what is often referred to as the middle atmosphere (10 to 110 $\mathrm{km})$. The MLT is dominated by the effects of atmospheric waves, including planetary waves, tides and gravity waves. The source regions for these waves are lower in the atmosphere. As the waves propagate upward their amplitudes grow exponentially to compensate for the decrease in atmospheric density (e.g. Andrews et al. 1987). Consequently, wave motions often dominate the wind field in the MLT, so considerable averaging may be required to extract the mean flow, especially that of the mean meridional (NS) motions, which are smaller than the zonal (EW) flow. Zonal-mean zonal winds are eastward (westward) in the winter (summer) middle atmosphere, reaching peak values of approximately 60 to $70 \mathrm{~ms}^{-1}$ near $70 \mathrm{~km}$ and

Correspondence: robert.vincent@adelaide.edu.au

Department of Physics, School of Physical Sciences, University of Adelaide,

North Terrace., SA, 5005 Adelaide, Australia then they reduce in magnitude until they reverse sign at heights between 90 and $100 \mathrm{~km}$.

Large wave amplitudes lead to wave breaking and hence momentum deposition. This, in turn, produces body forces that drive large scale residual circulations. In the winter stratosphere (approximately 20 to $60 \mathrm{~km}$ ), planetary wave breaking drives a residual circulation from the equator to the winter pole, while in the mesosphere, gravity wave breaking and dissipation drives a circulation from the summer to winter pole (e.g. see Andrews et al. 1987). The combined effects of these large-scale circulation patterns, usually referred to as the Brewer-Dobson circulation, can be profound. For example, the pole-topole circulation at the mesopause (approximately 85 to 90 $\mathrm{km}$ ) leads to rising (descending) motions over the summer (winter) pole with associated adiabatic cooling (heating). These vertical motions produce temperatures that are more than $50 \mathrm{~K}$ cooler or warmer than would be expected by radiative equilibrium alone. In fact the summer polar mesopause is the coldest place in the Earth's environment with temperatures of $120 \mathrm{~K}$ or lower. Temperatures below

\section{它 Springer}

(c) 2015 Vincent: licensee Springer. This is an Open Access article distributed under the terms of the Creative Commons Attribution License (http://creativecommons.org/licenses/by/4.0), which permits unrestricted use, distribution, and reproduction in any medium, provided the original work is properly credited. 
about $130 \mathrm{~K}$ are sufficient for ice particles to form, leading to a phenomena such as noctilucent clouds.

The mean pole-to-pole flow at the solstices is about $10 \mathrm{~ms}^{-1}$ at the mesopause, i.e. at the heights where the shears in the zonal-mean zonal winds are greatest. It is straightforward to calculate the body force required to maintain this meridional flow from the gravity wave flux divergence:

$$
\overline{F_{u}}=-\frac{1}{\rho_{o}} \frac{\partial\left(\rho_{o} \overline{u^{\prime} w^{\prime}}\right)}{\partial z}=f \bar{v} .
$$

Here, $\rho_{o}$ is the atmospheric density at height $z, \rho_{o} \overline{u^{\prime} w^{\prime}}$ is the mean upward flux of zonal momentum and $f$ is the Coriolis parameter. At the midlatitude mesopause with $\bar{v} \sim 10 \mathrm{~ms}^{-1}$ then $|\bar{F}| \sim 100 \mathrm{~ms}^{-1} \mathrm{day}^{-1}$. The corresponding mean vertical motions in the polar mesosphere are inferred to be about 4 to $5 \mathrm{~mm} \mathrm{~s}^{-1}$ (McIntyre 1989).

Of course, at equatorial latitudes $f \sim 0$ and so, wave driving goes directly into accelerating the mean flow, $\overline{F_{u}}=\partial \bar{u} / \partial t$. Wave driven phenomena include the quasibiennial-oscillation $(\mathrm{QBO})$ in the zonal-mean zonal winds in the lower and middle stratosphere (Baldwin et al. 2001) and semiannual oscillations at the equatorial stratopause and mesopause.

Any major disturbances in the stratosphere may significantly modify the gravity wave (GW) fluxes and hence may lead to significant changes in the thermal and wind structure of the MLT. Such disturbances include sudden stratospheric warmings (SSW) where the winds and temperature gradients in the polar stratosphere are reversed on the time scale of days to weeks. Alternatively, other large scale waves can transfer momentum to the MLT to partially offset GW driving. One such phenomenon is the quasi-two-day wave (QTDW), which is a transient wave event that can attain large amplitudes in the MLT.

Here, we review some aspects of middle atmosphere dynamics. Limited space means the review is not exhaustive but focusses on developments in the past decade. It includes discussions on tides, SSW and their effects, the equatorial middle atmosphere, the quasi-two-day wave and on observations of gravity waves, including wave sources, and their impact on the MLT.

\section{Atmospheric tides in the MLT}

Tidal oscillations in winds and temperatures are prominent features of the MLT. Periods of 24 (diurnal) or $12 \mathrm{~h}$ (semidiurnal) dominate. Careful averaging allows the $8 \mathrm{~h}$ (terdiurnal) and even lunar tides with a period of $12.4 \mathrm{~h}$ to be observed. Tides are usually classified as either migrating or non-migrating. That is, for a ground-based observer migrating (sun synchronous) tides appear to move westward at the same speed as the sun while non-migrating (sun asynchronous) tides move either eastwards or westwards relative to the sun.

Early work in tidal theory is described in Chapman and Lindzen (1970). Solar heating occurs through the absorption of infrared radiation by water vapour in the lower atmosphere and of UV radiation by ozone in the stratosphere. Classical tidal theory assumes a stationary, isothermal, atmosphere without dissipation. Incorporation of more realistic properties, such as height and latitudinally varying temperatures and background winds, requires numerical techniques to solve the relevant equations. In this regard, the development of mechanistic models such as the Global Scale Wave Model (GSWM) described by Hagan et al. (1999) have proved invaluable for the interpretation of tidal observations. The GSWM continues to evolve to include better heating rates and also the effects of non-radiative heating sources, such as tropospheric latent heat release, and the effect of of clouds (Hagan and Forbes 2002; Oberheide et al. 2002; Zhang et al. 2010a,b). High vertical-resolution climate models such as the Kyushu-GCM (Yoshikawa and Miyahara 2005) and the Canadian Middle Atmosphere Model (Xu et al. 2012) are also powerful tools for studying excitation mechanisms of non-migrating tides and interaction of tides with planetary and gravity waves and the interpretation of data.

Improvements in the understanding of tides came from better and more widespread observations. The establishment of ground-based radars at both equatorial and polar latitudes enhanced the spatial/temporal coverage originally available from the predominately mid-latitude stations that prevailed before 2000 (e.g. Mitchell et al. 2002; Sridharan et al. 2010; Nozawa et al. 2012; Davis et al. 2013). New instruments, notably lidars that provide daytime observations, also came on line (e.g She et al. 2002). In some respects, however, the most notable advances resulted from the deployment of satellite instruments such as the high-resolution Doppler interferometer (HRDI) on the Upper Atmosphere Research Satellite (UARS) in the 1990's (e.g see Burrage et al. 1995) and, in the last decade, the Sounding of the Atmosphere using Broadband Emission Radiometry (SABER) on the Thermosphere, Ionosphere, Mesosphere Energetics and Dynamics (TIMED) satellite (e.g. Mukhtarov et al. 2009).

Perhaps the most interesting finding to emerge from recent modelling and observational studies is that nonmigrating tides are often an important component of upper atmosphere dynamics. Figure 1 shows the zonal wind amplitude of the fundamental diurnal westward 1 (DW1) and eastward wave number 3 (DE3) tides derived from the Thermosphere Ionosphere Electrodynamics General Circulation Model (TIME-GCM) forced at is lower boundary by the GSWM in an equinox simulation (Hagan et al. 2009). DW1 propagates from the troposphere and peaks near $100 \mathrm{~km}$ altitude and $\pm 25^{\circ}$ latitude. 


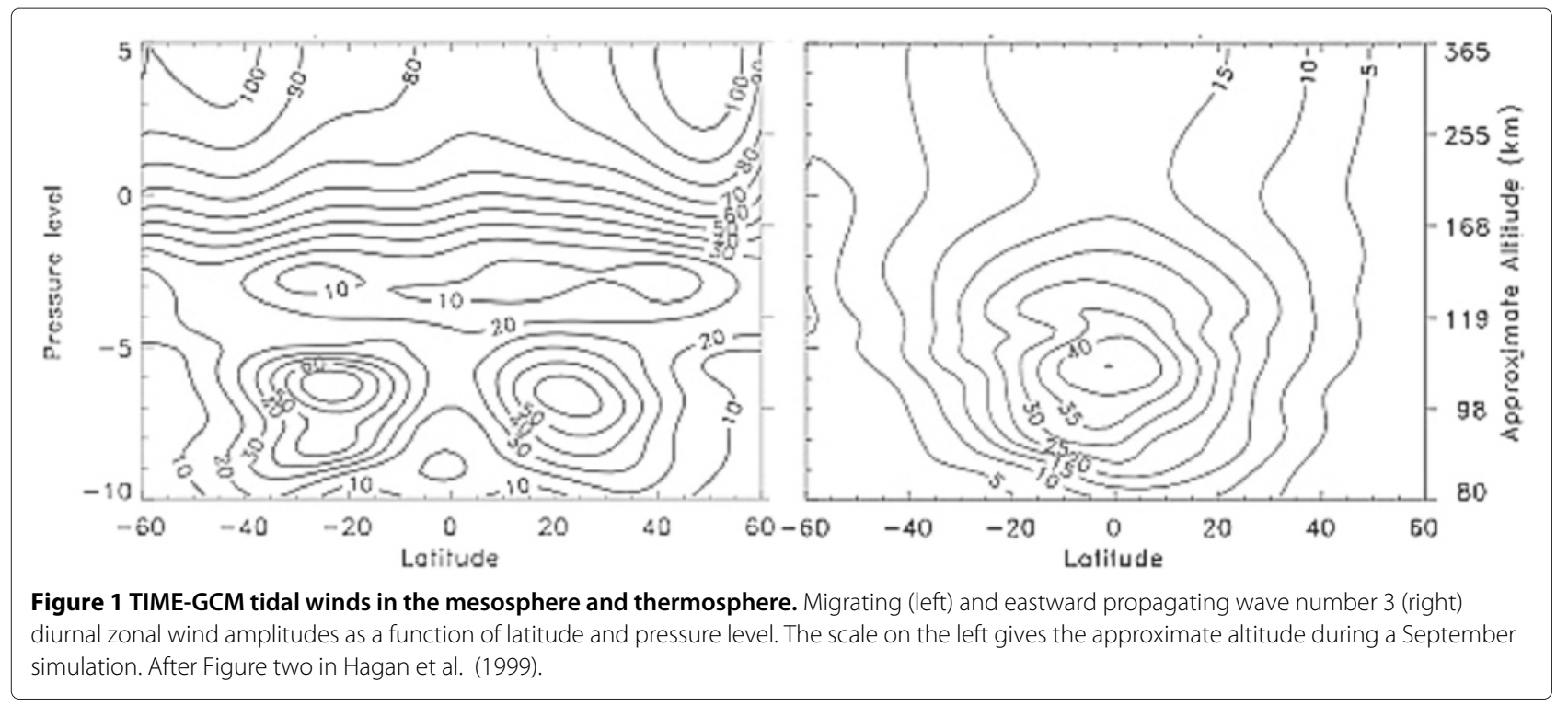

The DW1 component above approximately $120 \mathrm{~km}$ arises from absorption of solar EUV in the thermosphere and does not propagate energy and momentum vertically. The DE3 is forced in the troposphere and is confined to low latitudes, attaining peak amplitudes near $110 \mathrm{~km}$ but penetrating as a propagating tide well into the thermosphere. Interactions between the DW1 and DE3 can lead to secondary tidal and planetary waves (see Hagan et al. 2009 for details and reference to other works). The key point is that the DE3 and other non-migrating modes are substantial features of the upper MLT and can significantly impact the middle and upper atmosphere.

The broader perspective provided by ground-based networks to tidal studies is demonstrated by Murphy et al. (2006). Combining multi-year observations made by radars located around the periphery of the continent and at the South Pole they developed a climatology of the semidiurnal tide over the Antarctic, as shown in Figure 2

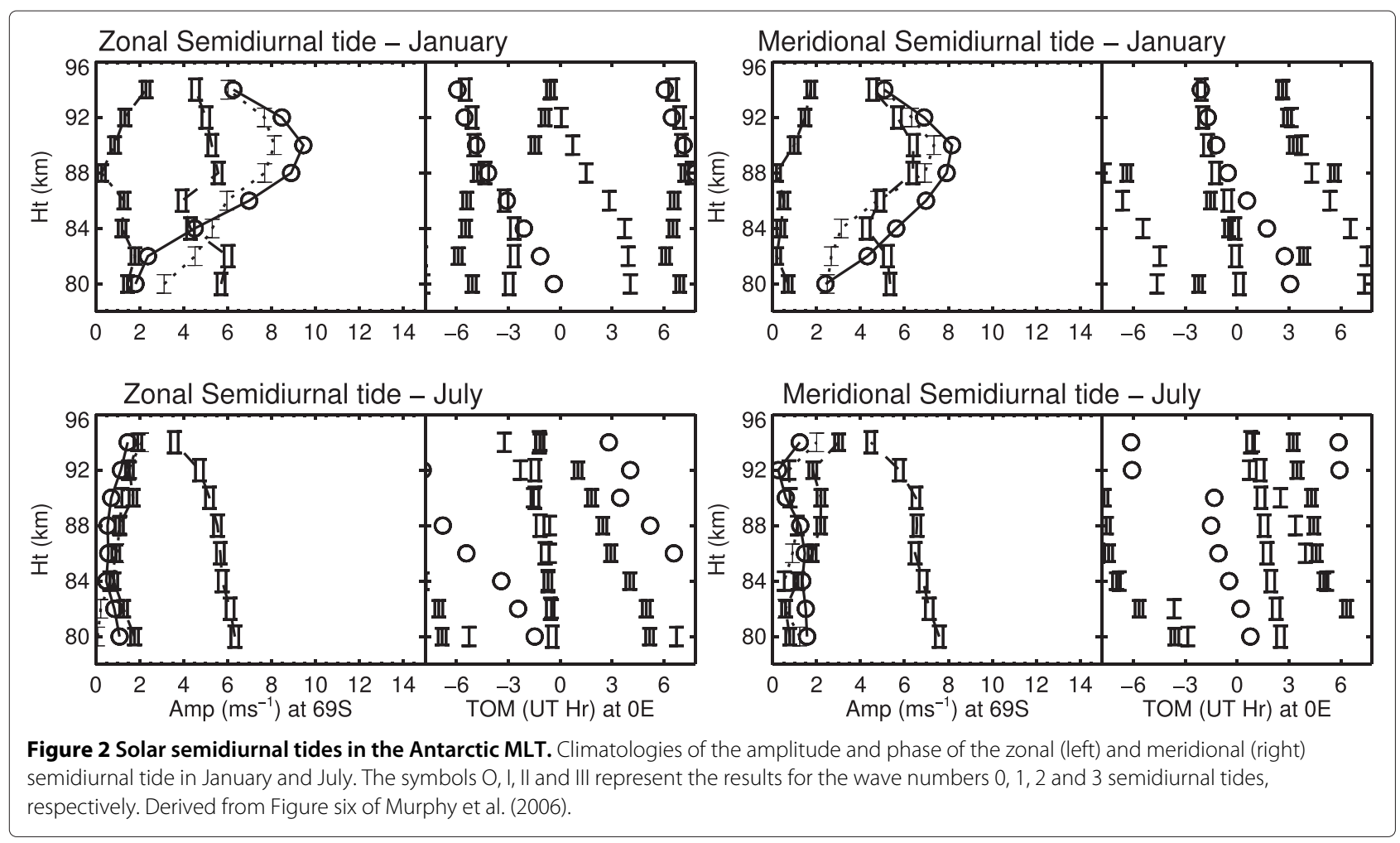


for the amplitudes and phases in summer (January) and winter (July). Note the strong presence of the SD1 and SD0 tidal modes in summer but their near absence in winter when the semidiurnal migrating SD2 mode is dominant. The excitation mechanisms of the non-migrating modes are not fully understood but probably arise through the interaction between the migrating mode and stationary planetary waves (Murphy et al. 2006).

These are just two examples of many recent studies that show the relative importance of non-migrating tides in the MLT. Their influence extends into the thermosphere/ionosphere. Immel et al. (2006) reported a modulation of $F$ region electron densities around the magnetic equator which they ascribed to the effects of non-migrating diurnal tides, such as the DE3 mode shown in Figure 1. However, the mechanisms that underly the coupling into the ionosphere are still a matter of debate. The most commonly proposed mechanism to explain this is an electrodynamic coupling between tides at $E$ region altitudes and ion drifts at $F$ region altitudes, but multiple-mechanisms involving electrodynamic and electro-chemical effects may be involved (England et al. 2010). Recently, Jones et al. (2013) assessed the relative effects of thermospheric tides generated in situ versus the effects of tides generated in the troposphere. Their results suggest that under certain conditions in situ-generated non-migrating tidal components dominate some parts of the tidal spectrum and must be taken into account.

\section{Sudden stratospheric warmings and their effects in the MLT}

A sudden stratospheric warming is a large-scale disruption of the wind and temperature fields of the wintertime polar stratosphere. SSW are usually classified as major or minor, although a continuum of warmings states may occur (Coughlin and Gray 2009). A major SSW is one in which the zonal-mean eastward winds around the pole cap temporarily reverse to summer-like conditions and the polar stratosphere warms so the NS temperature gradient is reversed from the normal wintertime situation. A minor warming is conventionally defined as one in which the temperature gradient reverses but the winds do not. Major SSW are primarily a northern hemisphere phenomena and occur approximately once or twice each winter. Only one major SSW has been observed in the southern hemisphere, in 2002 (e.g Krüger et al. 2005).

Figure 3 illustrates the impact on $10 \mathrm{hPa}$ temperatures and winds at $60 \mathrm{~N}$ of the January 2006 major SSW (Yamazaki et al. 2012). Note the reversal of the zonal wind between 21 January and 10 February. The effects of this and other major warmings can be found throughout the middle and upper atmosphere. Yamazaki et al. (2012) themselves found that the Sq current system driven by

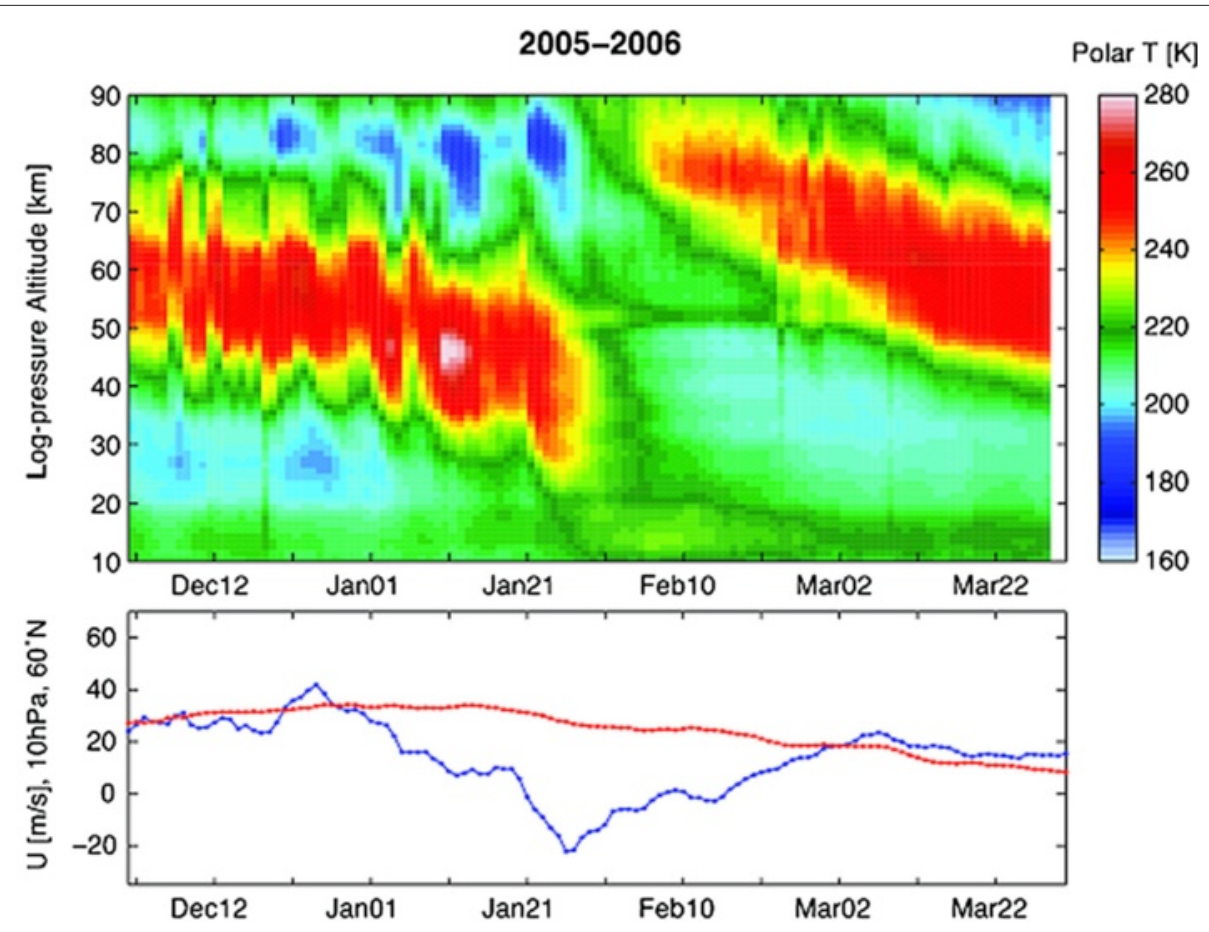

Figure $\mathbf{3}$ The $\mathbf{2 0 0 6}$ major sudden warming. Top: time-height cross-section of temperatures during the major SSW in late January 2006. Note the descent and disappearance of the stratopause at the peak of the warming and its subsequent reappearance and descent from the mesosphere. Bottom: the time variation of the zonal-mean zonal wind at $10 \mathrm{hPa}$ and $60 \mathrm{~N}$. The blue line shows the wind during the stratwarm, while the red line depicts the climatalogical seasonal cycle. Adapted from Figure one of Yamazaki et al. (2012). 
tides in the dynamo region (approximately 100 to $150 \mathrm{~km}$ ) is profoundly affected by major SSW.

Funke et al. (2010) reported on temperature anomalies in upper atmosphere during the January 2009 SSW. Cooling was observed in the mesosphere (approximately 90 $\mathrm{km}$ ) and warming at heights near $130 \mathrm{~km}$ (see Figure 4). Furthermore, the strength of the anomalies varied as a function of longitude, with a pronounced wave- 1 pattern. This effect is ascribed to a large planetary wave in the lower atmosphere imprinting its pattern in the upper atmosphere (Funke et al. 2010), as first suggested by Dunkerton and Butchart (1984). The changing wind and temperature fields in a warming spatially and temporally modulate GW fluxes in the stratosphere. When the waves dissipate, the resulting momentum deposition can leave its imprint in the MLT. This type of mechanism has been verified by Lieberman et al. (2013), who found the MLT circulation in various $\mathrm{NH}$ winters is qualitatively consistent with a simple model of wave forcing by drag from gravity waves that have been modulated by stratospheric planetary waves.

\section{Equatorial mesospheric zonal winds}

The equatorial middle atmosphere was poorly studied compared with the number of observations made at midand high latitudes. What information that was acquired came mainly from long-term radiosonde ascents at a few equatorial stations, such as Singapore $\left(1^{\circ} \mathrm{N}, 104^{\circ} \mathrm{E}\right)$, and from semi-regular rocket soundings made from Kwajalein $\left(9^{\circ} \mathrm{N}, 168^{\circ} \mathrm{W}\right)$ and Ascension Island $\left(8^{\circ} \mathrm{S}, 14^{\circ} \mathrm{W}\right)$. The long sequence of Singapore observations has been particularly important for the study of the QBO, while the rocket measurements led to the discovery and further investigation of semi-annual oscillations in the vicinity of the stratopause (SSAO) and mesopause (MSAO). Garcia et al. (1997) summarized early results.

The installation of radars at equatorial latitudes and space-based observations since 1990 (e.g. Vincent and Lesicar 1991, Burrage et al. 1996) now gives a much better understanding of variability in the at equatorial MLT. For example, Venkateswara Rao et al. (2012b) used approximately 20 years of ground-based radar wind measurements made at various sites in the tropical regions of Asia-Oceania in order to study MLT variability (Figure 5). By grouping observations from stations located at similar latitudes and averaging over all years they studied the equatorial wind field as a function of height and time, as shown in Figure 6. The plots provide more evidence for stronger westward winds in the March equinox than in September. There is also interannual variability on QBO time scales, with a significant enhancement in the March phase of the MSAO at a time when the QBO winds are in their eastward phase. However, there is decadal variability with this so-called MSAO enhancement less strong after 2002.

The causes of the MSAO are not fully understood. Garcia et al. (1997) noted an apparent link to the asymmetry in the strength of the stratospheric

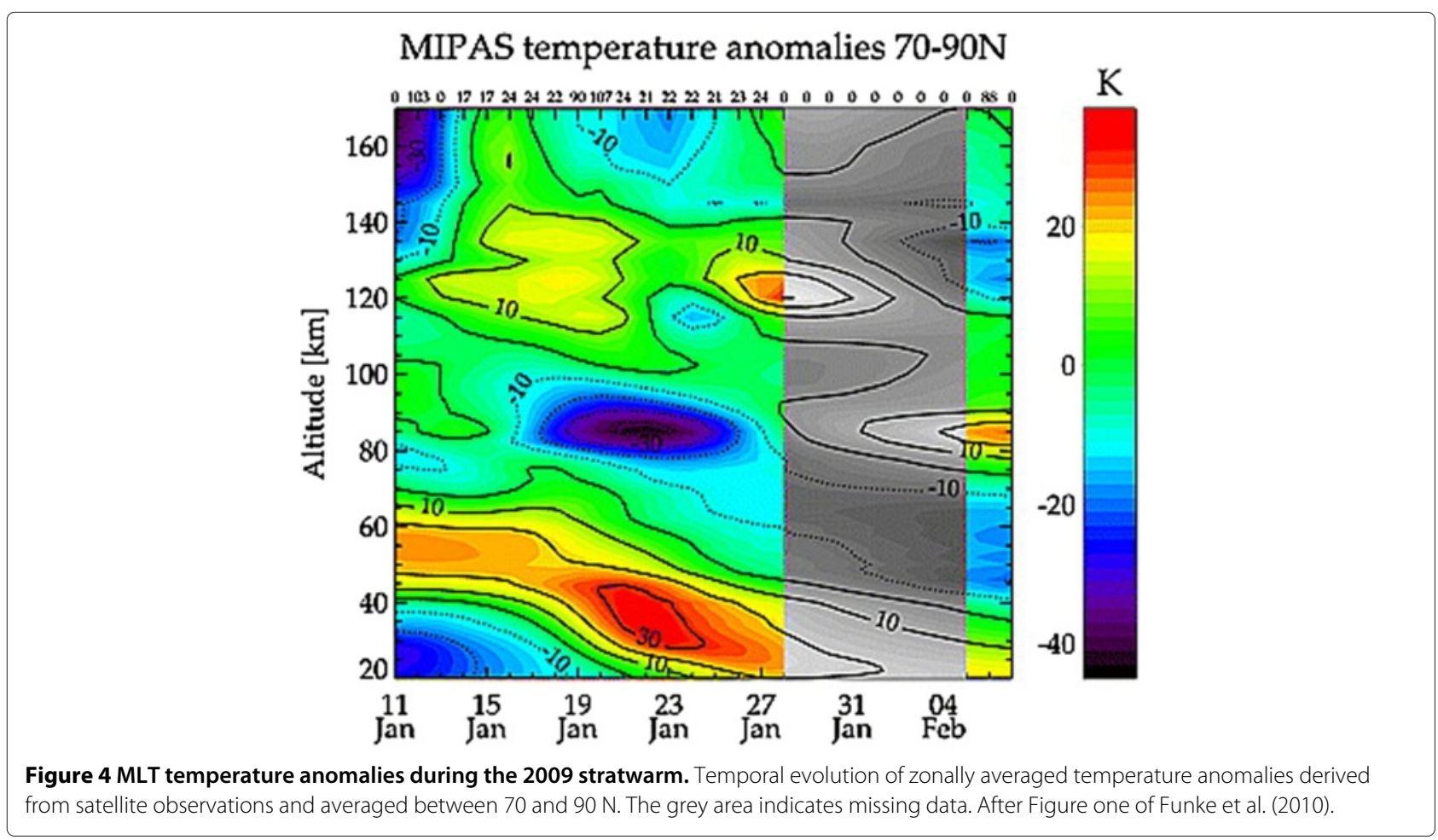




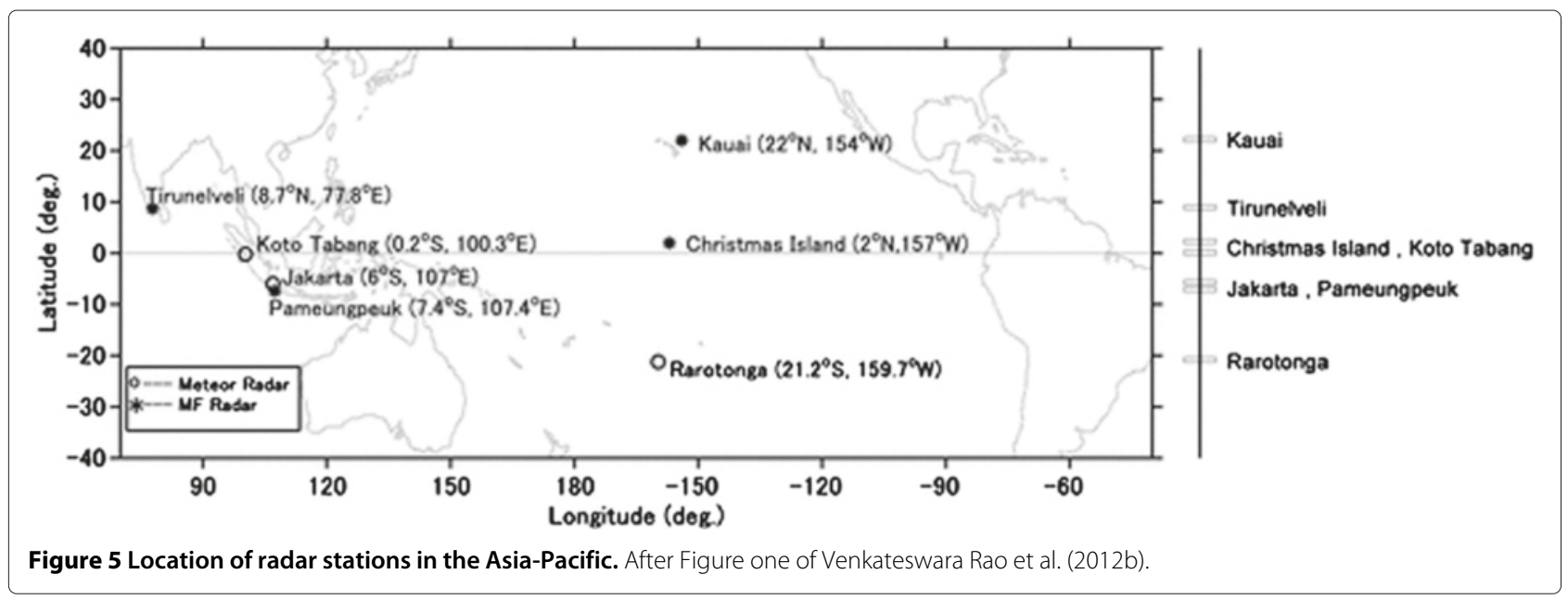

semiannual eastward winds, which also show a QBO-like enhancement at the March equinox. They postulated a role for small-scale gravity wave driving, although other wave modes may also be important. It should be remarked that a QBO-like link to the strength of propagating diurnal tide has been reported (Burrage et al. 1996; Vincent et al. 1998). Recently, Venkateswara Rao et al. (2012b) reported correlations between short-period gravity-wave variances at the mesopause and the strength of the MSAO observed using an MF radar in Indonesia. This result supports the GW momentum deposition drives the MSAO, but the issue is not likely to be fully resolved until momentum flux measurements can be made at the equator.

\section{The quasi-two-day wave and its impact on the MLT}

The QTDW is a westward travelling planetary wave that is of considerable interest because it can be one of the largest features of the MLT. It is a transitory phenomenon

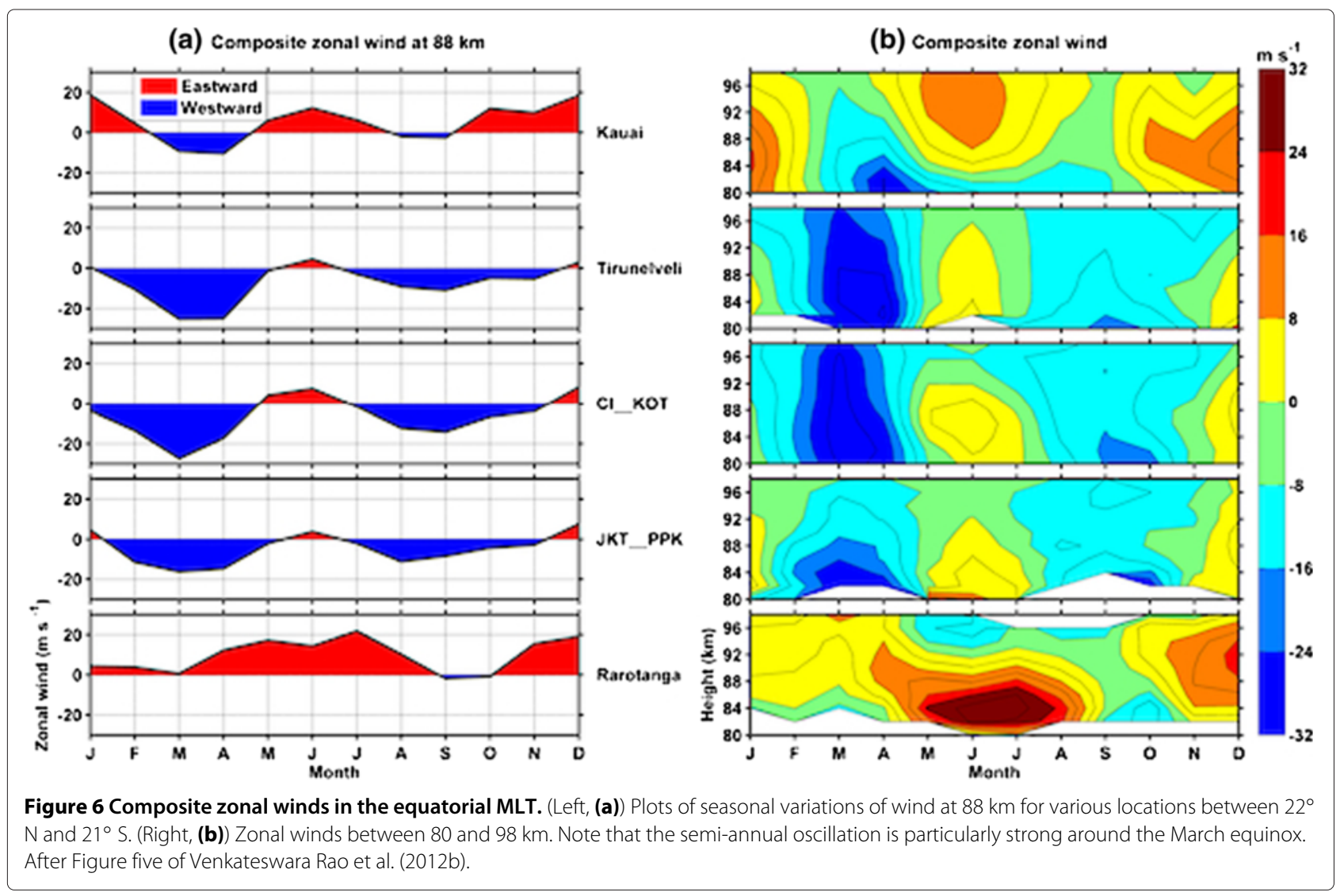


appearing after the summer solstice and is primarily a zonal wave number 3 phenomenon in the southern hemisphere but is often a mixture of wave numbers 3 and 4 components in the northern hemisphere. The QTDW is a manifestation of the wave- 3 normal mode but amplified by baroclinic instability of the summer westward jet near heights of $60 \mathrm{~km}$ (Plumb 1983). Using satellite measurements, Ern et al. (2013) explored how baroclinic instabilities in the mesospheric summer jet are linked to enhanced gravity-wave drag, which decelerates the jet and causes negative potential vorticity gradients.
Figure 7 illustrates many of the features of the QTDW observed in the southern hemisphere MLT. The NS wind measurements (Figure 7a) were made at $92 \mathrm{~km}$ with a meteor radar located at Darwin $\left(12^{\circ} \mathrm{S}, 131^{\circ} \mathrm{E}\right)$. Figure $7 b, c$ shows the amplitude and phase of the NS winds filtered with a bandpass between 40 and $60 \mathrm{~h}$, with the phase referenced to an oscillation with a period of $48 \mathrm{~h}$. In general, the increase of phase with time indicates a period less than $48 \mathrm{~h}$, but the steady phase observed between about day 21 and 29 shows the period at this time was close to $48 \mathrm{~h}$. The same behaviour was observed

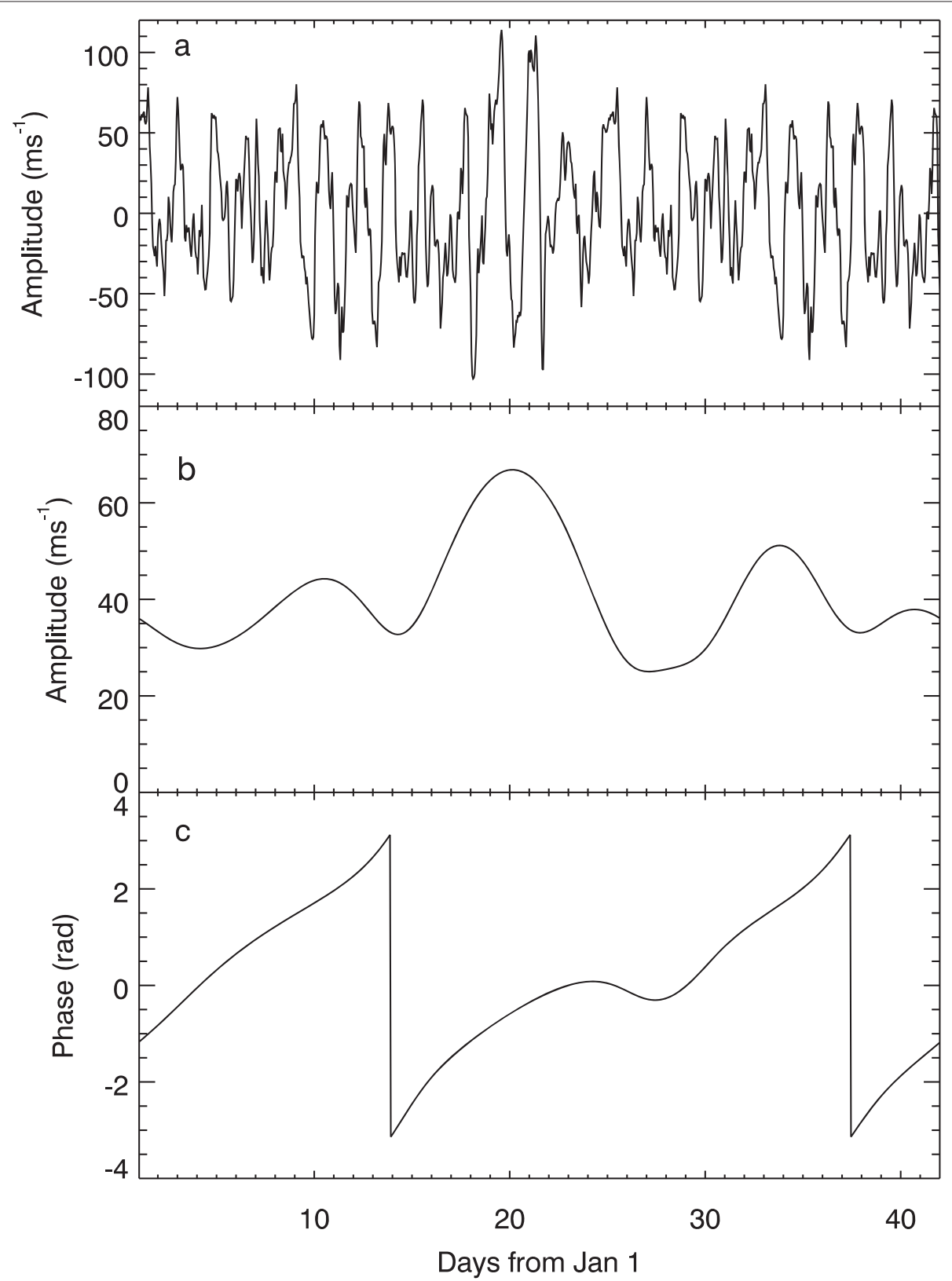

Figure 7 The QTDW in MLT winds at Darwin in 2006. (a) Time series of hourly average NS winds observed at $92 \mathrm{~km}$. (b) Amplitude of $48 \mathrm{~h}$ component of NS winds. (c) Phase of $48 \mathrm{~h}$ component. 
during the 2006 QTDW event at Adelaide by McCormack et al. (2010) who invoked phase locking through nonlinear interactions with the migrating diurnal tide, as proposed by Walterscheid and Vincent (1996). Studies of radar and airglow emissions from the MLT by Hecht et al. (2010) corroborated the phase-locking mechanism. They found the airglow intensity response was much larger than what would be expected from the airglow temperature response, suggesting that the QTDW is causing a significant composition change, possibly due to minor constituent transport. Combining temperature measurements made with the AURA and TIMED satellites Forbes and Moudden (2012) explored interactions between the QTDW and various tidal modes. A key finding was that large secondary waves were produced.

Amplitudes of up to $100 \mathrm{~ms}^{-1}$ in the NS wind component are often observed, but there is significant interannual variability (e.g. Siskind and McCormack 2014; Moudden and Forbes 2014). The SH QTDW attained large amplitudes in January 2004 and 2006 but not in 2008 to 2009 , for example. QTDW activity in the NH is uncorrelated with that in the $\mathrm{SH}$ and smaller in amplitude (Moudden and Forbes 2014).

Due to its large amplitude, the QTDW has significant impact on the MLT and higher. Plumb et al. (1987) first noted that the pulse-like QTDW event in January 1984 caused a temporary but substantial change in the prevailing circulation of the MLT. Short-term effects due to the QTDW may explain the interannual variability of brightness of southern polar mesospheric clouds (PMC), which form as a consequence of the cold mesospheric temperatures at the summer pole (e.g. Pendlebury 2012). In large amplitude QTDW years, the brightness of southern PMC is reduced. Siskind and McCormack (2014) ascribe this effect to the QTDW depositing westward momentum that, acting through the Coriolis torque in Equation one, produces a southward flow that partially offsets the GW-driven equatorward, northward wind. Hence, there is a corresponding reduction in the upward motions at the pole with an accompanying reduction in the adiabatic cooling, leading to a temperature increase at the polar mesopause.

Just as the effect of large stratospheric warming events may be felt in the thermosphere/ionosphere, so can the QTDW influence the ionosphere. Yue et al. (2012) used the TIME-GCM to explore how the QTDW modulates the dynamo electric field and map into the ionosphere. Through case studies, Chang et al. (2014) describe how the QTDW drives variability in composition and ionospheric total electron content.

\section{Gravity waves and their effect in the MLT}

As noted in the 'Introduction' subsection, momentum deposition by gravity waves plays a crucial role in determining the state of the middle atmosphere. Incorporation of GW effects in climate models is a pressing problem (Alexander et al. 2010). Consequently, a wide range of techniques have been applied to determine wave parameters such as horizontal and vertical wavelengths and phase speeds. Each technique has its own strengths and limitations. Satellites provide a global perspective, but their viewing geometry determines the vertical and horizontal resolutions that can be attained (see Alexander and Barnet 2007). Ground-based radars and radiosonde have good temporal but limited horizontal resolution. Superpressure balloon (SPB) techniques are unique in that they measure gravity wave parameters as a function of intrinsic frequency but only at the float altitude near $18 \mathrm{~km}$. Alexander et al. (2010) review the overall ability of the various techniques to determine important $\mathrm{GW}$ parameters.

One way to determine gravity wave activity is to use temperature soundings. The potential energy is then:

$$
E_{p}=\frac{1}{2}\left(\frac{g}{N}\right)^{2} \overline{\left(\frac{T^{\prime}}{T_{o}}\right)^{2}}
$$

where $T^{\prime}$ is the GW-induced temperature perturbation from the mean temperature $T_{o}$. Using this methodology, Zhang et al. (2012) and Wang et al. (2005) produced maps of wave activity in the stratosphere, while Hoffmann et al. (2013) focussed on locating GW 'hot spots'. They found high stratospheric wave activity over regions of strong convection in summer (e.g. the Amazon Basin) and mountain wave activity in winter (e.g. southern Andes and Antarctic Peninsula). Alexander et al. (2008) used limbsounding GPS/COSMIC observations to study the temporal evolution of wave activity over the equator. They found evidence for vertically propagating convectively generated gravity waves interacting with the background mean flow. Enhancements in $E_{p}$ around descending QBO eastward shear lines suggest a wave-mean flow interaction.

An interesting development in the past two decades has been the use of high vertical-resolution radiosondes regularly launched by weather agencies to investigate spatial variability in GW activity (Allen and Vincent 1995). Initially used to study potential energies, radiosonde studies were extended to include wave kinetic energies $\left(E_{k}=\right.$ $u^{\prime 2}+v^{\prime 2}$ ). Using the extensive United States radiosonde network, Wang and Geller (2003) investigated spatial and seasonal variability of wave activity across the USA and its dependencies from the Arctic to South Pacific. This work was important for distinguishing source from propagation effects in determining wave variability. For example, they found that tropospheric GW energy $\left(E_{p}+E_{k}\right)$ maximises over the Rocky Mountains, indicating a mountain wave source. However, in the lower stratosphere, the energy maxima are mostly in the southeastern United States. 
QBO and El Nino-Southern Oscillation effects appear to account for much of the observed interannual variability in lower stratospheric wave energy. Their work was extended by Wang et al. (2005) and Gong et al. (2008) to studies of other important GW parameters, such as horizontal wavelengths and source spectra.

GW potential energies can be converted into absolute momentum fluxes if the horizontal $\left(\lambda_{h}\right)$ and vertical wavelengths $\left(\lambda_{z}\right)$ are known viz:

$$
\rho_{o}\left|\overline{u^{\prime} w^{\prime}}\right|=\frac{1}{2} \rho_{o} \frac{\lambda_{z}}{\lambda_{h}}\left(\frac{g}{N}\right)^{2} \overline{\left(\frac{T^{\prime}}{T_{o}}\right)^{2}}
$$

A downward viewing instruments on satellite can be used to determine $\lambda_{h}$ by locating similar temperature features on horizontally separated scans. Different instruments have different capabilities, as illustrated in Figure 8, as discussed by Ern et al. (2011). The vertical wavelength is determined from scale of the temperature oscillations on each scan and is obviously limited by the vertical resolution of the instrument. Ern et al. (2011) applied the methodology through the stratosphere and lower mesosphere, with strong fluxes captured at latitudes greater than $50^{\circ}$ in local winter and near $25^{\circ}$ in the subtropics in summer. Figure 9 illustrates observations made with the SABER instrument on the TIMED satellite. Momentum flux values are enhanced in the polar night jets at midand high latitudes and in the subtropics of the summer hemisphere over the monsoon regions, forming a very characteristic zonal triple structure in the northern hemisphere and a triple or quadruple structure in the southern hemisphere. It is noteworthy that the momentum flux distribution at $70 \mathrm{~km}$ in the lower mesosphere has a different geographic distribution to that at $30 \mathrm{~km}$.

Absolute fluxes are useful for constraining GW parameterization schemes used in climate models but is better to use signed momentum $\left(\rho_{o} \overline{u^{\prime} w^{\prime}}, \rho_{o} \overline{v^{\prime} w^{\prime}}\right)$ fluxes as a function of intrinsic frequency. Such measurements can be made with SPB, albeit only at one height (Hertzog et al. 2008). Figure 10 shows spectra of the GW momentum flux for SPB flights over the Antarctic during September and October 2010. The float altitude is about $18 \mathrm{~km}$. Note the sharp cut-offs at periods of about 4.5 and $600 \mathrm{~min}$, which correspond to the Väisälä-Brunt and inertial periods, respectively. The peak at a period near $150 \mathrm{~min}$, corresponding to horizontal scales approximately $100 \mathrm{~km}$, is due to orographic waves located over the Antarctic Peninsula, a strong source of such waves (Hertzog et al. 2008). Also note the preponderance of upgoing fluxes, with about $70 \%$ of the total flux up-going. This reinforces our understanding that the majority of GW are generated in the lower atmosphere, with the spectrum being modified as the waves propagate upward. Parts of the spectrum will be lost due to wave reflection and dissipation so the spectrum in the MLT is likely to look quite different to that shown in Figure 10.

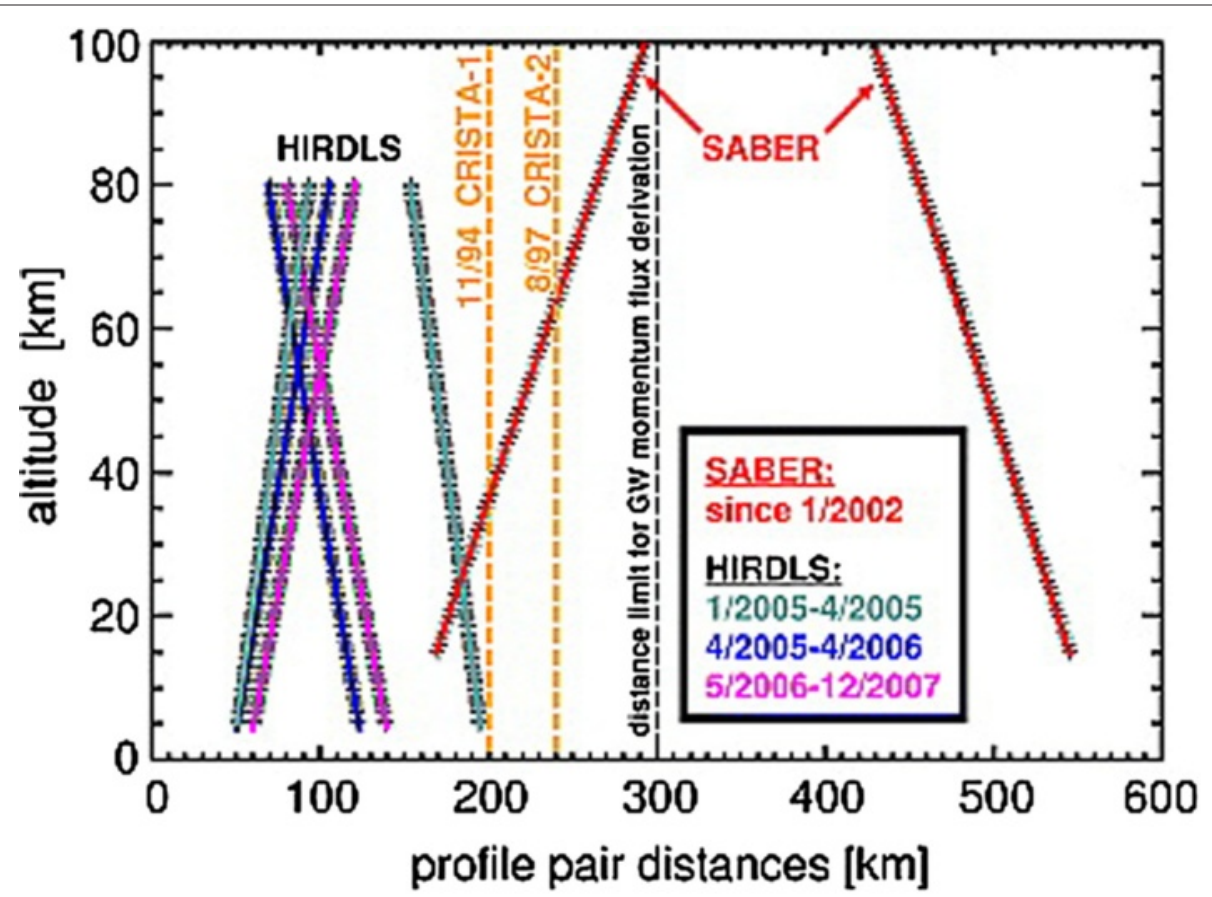

Figure 8 Examples of satellite scan patterns. Horizontal distance between sequential altitude profiles along the measurement tracks for the CRISTA, HIRDLS and SABER instruments. After Figure one of Ern et al. (2011). 


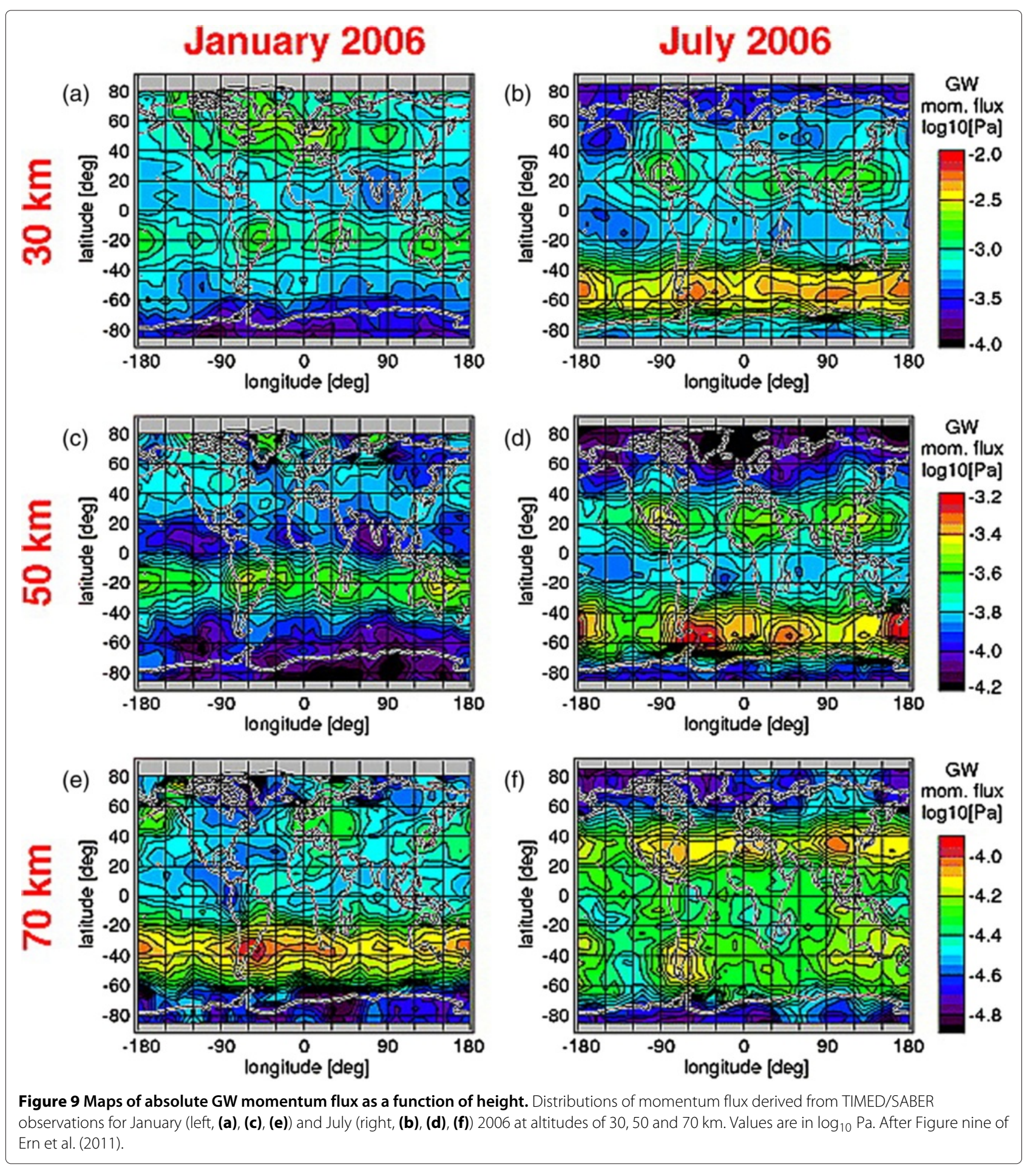

Observations of individual wave generation and coupling events through the middle atmosphere give important insights into wave generation and propagation. Hoffmann and Alexander (2009) used satellite data to study waves generated by convection over Darwin and a strong mountain wave over Patagonia. The latter event had a vertical wavelength of approximately 7 to $15 \mathrm{~km}$ and could be followed directly through the stratosphere up to $60 \mathrm{~km}$ altitude.

Observations of large amplitude GWs raises the question of whether the body force of $\bar{F} \sim 100 \mathrm{~ms}^{-1}$ day $^{-1}$ required in the MLT is maintained by continuous 


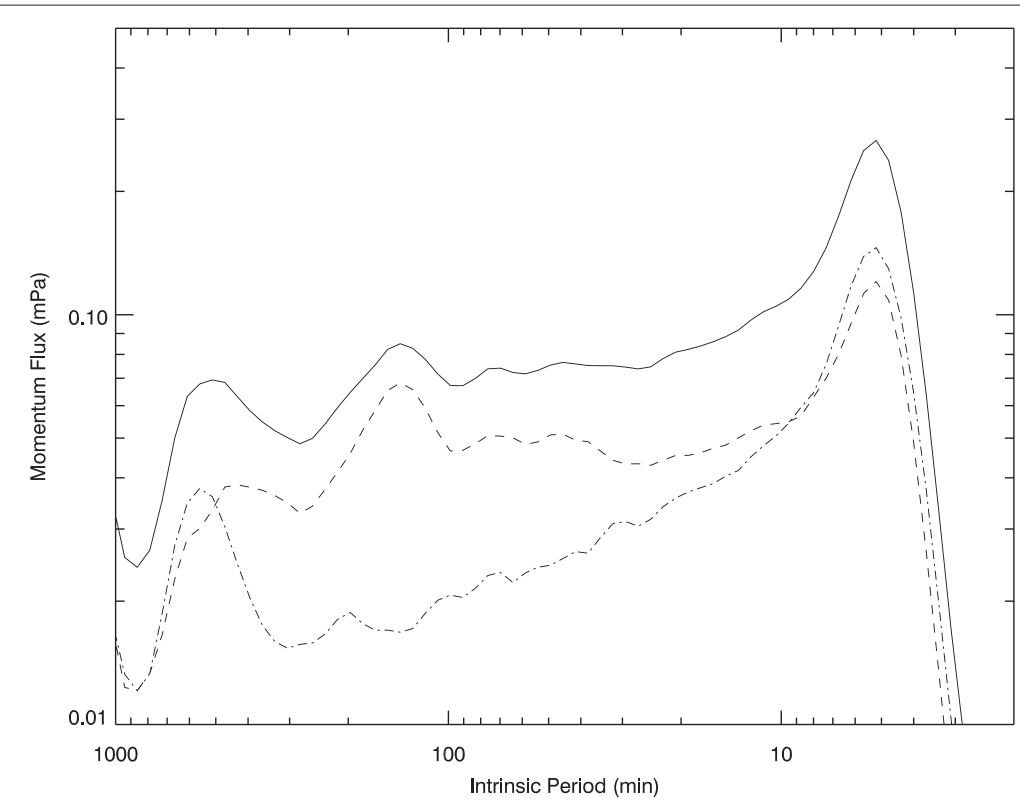

Figure 10 Momentum flux spectrum. Spectra of momentum flux $\left(\rho_{\circ} \overline{u^{\prime} W^{\prime}}\right)$ in mPa for total (solid), upward going (dashed) and downward going fluxes (dash-dot) derived from SPB observations over Antarctica, September to October 2010.

gravity wave breaking or by intermittent breaking of large amplitude waves. By considering GW generation by an isolated large convective event over Darwin, Vincent et al. (2013) were able to trace wave propagation through the middle atmosphere to heights where wave breaking created body forces of approximately 200 to $300 \mathrm{~ms}^{-1}$ day $^{-1}$ for a duration of a few hours. They noted that there was about 12 such convective events per day over the whole of tropical northern Australia and Indonesia during the monsoon season. Similarly, Hertzog et al. (2008) showed that strong intermittency was a feature of mountain waves observed over the Antarctic Peninsula. Intermittency of strong wave events supports the conjecture of Fritts and Vadas (2002) that the force required to close the mesospheric jets is sporadic in space and time.

\section{Conclusions}

In the past decade, there have been considerable improvements in our understanding of MLT dynamics, improvements driven in part by the development and deployment of new instruments and techniques. The importance of waves in the MLT is emphasised here because they dominate the wind and temperature fields of this region, so the MLT is a natural laboratory for the investigation of atmospheric waves and their effects.

Satellites, a wider deployment of ground-based radars and improved modelling capabilities means that the middle atmosphere is now investigated on a global scale and the relative contribution of different waves to the energy and momentum budgets are better understood. While the focus is on observational studies, especially of smallscale gravity waves, a notable advance in understanding has occurred through the development and application of very-high resolution general circulation models. In particular, the KANTO model resolves individual gravity waves in a realistic manner (Watanabe et al. 2008). Using this model, Sato et al. (2009) provide a global view of GW sources and propagation effects and the impact of GW on the momentum balance of the mesosphere.

Oscillations in winds and temperatures due to tides and other planetary-scale waves such as the QTDW are prominent features of the MLT. Wave-wave interactions lead to secondary waves that may also have substantial amplitude and which may be important for phase-locking the QTDW, for example. Tide/gravity wave interactions may produce either growth/acceleration or damping/retardation of tidal amplitudes and phases. Full understanding of the possible effects will come only from better observations and modelling.

Although waves and their effects dominate the MLT, their source regions lie mainly in the lower atmosphere. Consequently, wave impacts on the MLT ultimately depend on source variability and the varying transmission effects in the middle atmosphere. Such effects can lead to 'imprinting', which is especially noticeable at the equator where the mesospheric semiannual oscillation often seems to have a signature of the QBO superimposed upon it. Similarly, wave processing in the MLT will modify the spectrum of waves propagating higher into the 
thermosphere and ionosphere, leading to the imprinting of MLT effects at higher altitudes.

Investigation of individual wave events leads to a better understanding of wave impacts in the MLT. On planetary scales, large quasi-two-day wave events produce transitory changes to the circulation at the mesopause, leading to changes in the thermal structure at high latitudes with concomitant changes in the micro-physics of this region. At small scales, gravity waves play a preeminent role in the momentum budget of the MLT. It remains to be seen, however, whether the momentum deposition comes from a few sporadic large amplitude wave events or through deposition by many small amplitude waves. Resolution of this issue will only come from future observational and modelling efforts.

\section{Abbreviations}

GCM: global climate model; GSWM: Global Scale Wave Model; GW: gravity wave; MLT: mesosphere-lower thermosphere; QTDW: quasi-two-day wave; PMC: polar mesospheric cloud.

\section{Competing interests}

The author declares that he has no competing interest.

\section{Acknowledgements}

The helpful comments by M. A. Geller on an earlier draft of this paper are appreciated. D. J. Murphy is thanked for his help with Figure 2.

Received: 15 October 2014 Accepted: 17 February 2015

Published online: 18 March 2015

\section{References}

Alexander MJ, Barnet C (2007) Using satellite observations to constrain parameterizations of gravity wave effects for global models. J Atmos Sci 64:1652-1665

Alexander SP, Tsuda T, Kawatani Y, Takahashi M (2008) Global distribution of atmospheric waves in the equatorial upper troposphere and lower stratosphere: cosmic observations of wave mean flow interactions. J Geophys Res 113(D24):24115. doi:10.1029/2008JD010039

Alexander MJ, Geller M, McLandress C, Polavarapu S, Preusse P, Sassi F, Sato K, Ern M, Hertzog A, Kawatani Y, Pulido M, Shaw T, Sigmond M, Vincent R, Watanabe S (2010) Recent developments in gravity wave effects in climate models and the global distribution of gravity wave momentum flux from observations and models. QJR Meteorol Soc 136:1103-1124

Allen SJ, Vincent RA (1995) Gravity wave activity in the lower atmosphere: seasonal and latitudinal variations. J Geophys Res 100:1327-1350

Andrews DG, Holton JR, Leovy CB (1987) Middle atmosphere dynamics. Academic Press, London

Baldwin MP, Gray LJ, Dunkerton TJ, Hamilton K, Haynes PH, Randel WJ, Holton JR, Alexander MJ, Hirota I, Horinouchi T, Jones DBA, Kinnersley JS, Marquardt C, Sato K, Takahashi M (2001) The quasi-biennial oscillation. Rev Geophys 39(2):179-229. doi:10.1029/1999RG000073

Burrage MD, Hagan ME, Skinner WR, WU DL, Hays PB (1995) Long term variability in the solar diurnal tide observed by HRDI and simulated by the GSWM. Geophys Res Lett 22:2641-2644. doi:10.1029/95GL02635

Burrage MD, Vincent RA, Mayr HG, Skinner WR, Arnold PB, Hays N F (1996) Long-term variability in the equatorial mesosphere and lower thermosphere zonal wind. J Geophys Res 101:12847-12854

Chapman S, Lindzen RS (1970) Atmospheric tides. D. Reidel, Dordrecht, Holland

Chang LC, Yue J, Wang W, Wu Q, Meier RR (2014) Quasi two day wave-related variability in the background dynamics and composition of the mesosphere/thermosphere and the ionosphere. Journal of Geophysical Research: Space Physics 119(6):4786-4808. doi:10.1002/2014JA019936

Coughlin K, Gray LJ (2009) A continuum of sudden stratospheric warmings. J Atmos Sci 66(2):531-540
Davis RN, Du J, Smith AK, Ward WE, Mitchell NJ (2013) The diurnal and semidiurnal tides over ascension island $\left(8^{\circ} \mathrm{S}, 14^{\circ} \mathrm{W}\right)$ and their interaction with the stratospheric quasi-biennial oscillation: studies with meteor radar, eCMAM and WACCM. Atmos Chem Phys 13(18):9543-9564. doi:10.5194/ acp-13-9543-2013

Dunkerton TJ, Butchart N (1984) Propagation and selective tranmission of inertial gravity waves in a sudden warming. J Atmos Sci 41:1443-1460

England SL, Immel TJ, Huba JD, Hagan ME, Maute A, DeMajistre R (2010) Modeling of multiple effects of atmospheric tides on the ionosphere: an examination of possible coupling mechanisms responsible for the longitudinal structure of the equatorial ionosphere. J Geophys Res 115:05308. doi:10.1029/2009JA014894

Ern M, Preusse P, Gille JC, Hepplewhite CL, Mlynczak MG, Russell JM, Riese M (2011) Implications for atmospheric dynamics derived from global observations of gravity wave momentum flux in stratosphere and mesosphere. J Geophys Res 116(D19):19107. doi:10.1029/2011JD015821

Ern M, Preusse P, Kalisch S, Kaufmann M, Riese M (2013) Role of gravity waves in the forcing of quasi two-day waves in the mesosphere: an observational study. J Geophys Res 118:3467-3485. doi:10.1029/2012JD018208

Forbes JM, Moudden Y (2012) Quasi-two-day wave-tide interactions as revealed in satellite observations. Journal of Geophysical Research: Atmospheres 117(D12):12110. doi:10.1029/2011JD017114

Fritts DC, Vadas SL (2002) An estimation of strong local body forcing and gravity wave radiation based on $\mathrm{OH}$ airglow and meteor radar observations. Geophys Res Lett 29 26(10):71-1-71-4. doi:10.1029/2001GL013753

Funke B, López-Puertas M, Bermejo-Pantaleón D, Garcla-Comas M, Stiller GP, von Clarmann T, Kiefer M, Linden A (2010) Evidence for dynamical coupling from the lower atmosphere to the thermosphere during a major stratospheric warming. Geophys Res Lett 37:13803. doi:10.1029/ 2010GL043619

Garcia RR, Dunkerton TJ, Lieberman RS, Vincent RA (1997) Climatology of the semiannual oscillation of the tropical middle atmosphere. J Geophys Res 102:26019-26032

Gong J, Geller MA, Wang L (2008) Source spectra information derived from U.S. high-resolution radiosonde data. J Geophys Res 113:10106. doi:10.1029/ 2007JD009252

Hagan ME, Burrage MD, Forbes JM, Hackney J, Randel WJ, Zhang X (1999) GSWM-98: results for migrating solar tides. J Geophys Res 104:6813-6828

Hagan ME, Forbes JM (2002) Migrating and nonmigrating diurnal tides in the middle and upper atmosphere excited by tropospheric latent heat release. J Geophys Res 107(D24):4754

Hagan ME, Maude A, Roble RG (2009) Tropospheric tidal effects on the middle and upper atmosphere. J Geophys Res 114:01302. doi:10.1029/ 2008JA013637

Hecht JH, Walterscheid RL, Gelinas L, Vincent RA, Reid IM, Woithe JM (2010) Observations of the phase-locked 2 day wave over the australian sector using medium-frequency radar and airglow data. Journal of Geophysical Research: Atmospheres 115(D16):1-22. doi:10.1029/2009JD013772

Hertzog A, Boccara G, Vincent RA, Vial F, Cocquerez P (2008) Estimation of gravity-wave momentum fluxes and phase speeds from quasi-lagrangian stratospheric balloon flights. 2: Results from the Vorcore campaign in Antarctica. J Atmos Sci 65:3056-3070

Hoffmann L, Alexander MJ (2009) Retrieval of stratospheric temperatures from atmospheric infrared sounder radiance measurements for gravity wave studies. J Geophys Res 114:07105. doi:10.1029/2008JD011241

Hoffmann L, Xue X, Alexander MJ (2013) A global view of stratospheric gravity wave hotspots located with Atmospheric Infrared Sounder observations. J Geophys Res 118:416-434. doi:10.1029/2012JD018658

Immel TJ, Sagawa E, England SL, Henderson SB, Hagan ME, Mende SB, Frey HU, Swenson CM, Paxton LJ (2006) Control of equatorial ionospheric morphology by atmospheric tides. Geophys Res Lett 33:15108. doi:10.1029/ 2006GL026161

Jones M, Forbes JM, Hagan ME, Maute A (2013) Non-migrating tides in the ionosphere-thermosphere: in situ versus tropospheric sources. J Geophys Res 118(5):2438-2451

Krüger K, Naujcot B, Labitzke K (2005) The unusual midwinter warming in the southern hemisphere stratosphere 2002: a comparison to northern hemisphere phenomena. J Atmos Sci 62:603-613

Lieberman RS, Riggin DM, Siskind DE (2013) Stationary waves in the wintertime mesosphere: evidence for gravity wave filtering by stratospheric planetary waves. J Geophys Res 118(8):3139-3149. doi:10.1002/jgrd.50319 
McCormack JP, Eckermann SD, Hoppel KW, Vincent RA (2010) Amplification of the quasi-two day wave through nonlinear interaction with the migrating diurnal tide. Geophys Res Lett. doi:10.1029/2010GL043906

McIntyre ME (1989) On dynamics and transport near the polar mesopause in summer. J Geophys Res 94:14617-14628

Mitchell NJ, Pancheva D, Middleton HR, Hagan ME (2002) Mean winds and tides in the arctic mesosphere and lower thermosphere. J Geophys Res 107(A1):1004

Moudden Y, Forbes JM (2014) Quasi-two-day wave structure, interannual variability and tidal interactions furing the 2002-2011 decade. J Geophys Res 119(5):2241-2260. doi:10.1002/2013JD020563

Mukhtarov P, Pancheva D, Andonov B (2009) Global structure and seasonal and interannual variability of the migrating diurnal tide seen in the SABER/TIMED temperatures between 20 and $120 \mathrm{~km}$. J Geophys Res 114:03104. doi:10.1029/2008GL036535

Murphy DJ, Forbes JM, Walterscheid RL, Hagan ME, Avery SK, Aso T, Fraser GJ, Fritts DC, Jarvis MJ, McDonald AJ, Riggin DM, Tsutsumi M, Vincent RA (2006) A climatology of tides in the antarctic mesosphere and lower thermosphere. J Geophys Res 111:23104. doi:10.1029/2005JD006803

Nozawa S, Hall CM, Tsutsumi M, Brekke A, Ogawa Y, Tsuda TT, Oyama S, Fujii R (2012) Mean winds, tides, and quasi-2 day waves above bear island. J Atmos Solar-Terr Phys 0:26-44

Oberheide J, Hagan ME, Roble RG, Offermann D (2002) Sources of nonmigrating tides in the tropical middle atmosphere. J Geophys Res 107(D21):4567

Pendlebury D (2012) A simulation of the quasi-two-day wave and its effect on variability of summertime mesopause temperatures. J Atmos Solar-Terr Phys 80(0):138-151. doi:10.1016/j.jastp.2012.01.006

Plumb RA (1983) Baroclinic instability at the summer mesosphere: a mechanism for the quasi-two-day wave? J Atmos Sci 40:262-270

Plumb RA, Vincent RA, Craig RL (1987) The quasi-two-day wave event of january 1984 and its impact on the mean mesospheric circulation. J Atmos Sci 44:3030-3036

Sato K, Watanabe S, Kawatani Y, Amd K, Miyazaki Y T, Takahashi M (2009) On the origins of mesospheric gravity waves. Geophys Res Lett 36:19801. doi:10.1029/2009GL039908

She CY, Chen S, Williams BP, Hu Z, Krueger DA, Hagan ME (2002) Tides in the mesopause region over Fort Collins, Colorado $\left(41^{\circ} \mathrm{N}, 105^{\circ} \mathrm{W}\right)$ based on lidar temperature observations covering full diurnal cycles. J Geophys Res 107(D18):1-12

Siskind DE, McCormack JP (2014) Summer mesospheric warmings and the quasi 2 day wave. Geophys Res Lett 41(2):717-722. doi:10.1002/ 2013GL058875

Sridharan S, Tsuda T, Gurubaran S (2010) Long-term tendencies in the mesosphere/lower thermosphere mean winds and tides as observed by medium-frequency radar at tirunelveli $\left(8.7^{\circ} \mathrm{n}, 77.8^{\circ} \mathrm{e}\right)$. J Geophys Res 115(D8):08109. 0148-0227

Vincent RA, Lesicar D (1991) Dynamics of the equatorial mesosphere: first results with a new generation partial reflection radar. Geophys Res Lett 18:825-828

Vincent RA, S K, Fritts DC, Isler JR (1998) Long-term MF radar observations of solar tides in the low-latitude mesosphere: interannual variability and comparisons with the GSWM. J Geophys Res 103(D8):8667-8683

Vincent RA, Alexander MJ, Dolman BK, MacKinnon AD, May PT, Kovalam S, Reid IM (2013) Gravity wave generation by convection and momentum deposition in the mesosphere-lower thermosphere. J Geophys Res 118:6233-6245. doi:10.1002/jgrd.50372

Venkateswara Rao N, Tsuda T, Kawatani Y (2012b) A remarkable correlation between short period gravity waves and semiannual oscillation of the zonal wind in the equatorial mesopause region. Ann Geophys 30:703-710. doi:10.5194/angeo-30-703-2012

Venkateswara Rao N, Tsuda T, Riggin DM, Gurubaran S, Reid IM, Vincent RA (2012b) Long-term variability of mean winds in the mesosphere and lower thermosphere at low latitudes. J Geophys Res 117(10):1-16. doi:10.1029/ 2012JA017850

Walterscheid RL, Vincent RA (1996) The tidal generation of phase locked two-day wave in the southern hemisphere by wave-wave interactions. J Geophys Res 101:26567-26576

Wang L, Geller MA (2003) Morphology of gravity-wave energy as observed from 4 years (1998-2001) of high vertical resolution U.S. radiosonde data. J Geophys Res 108:4489. doi:10.1029/2002JD002786
Wang L, Geller MA, Alexander MJ (2005) Spatial and temporal variations of gravity wave parameters. part i: intrinsic frequency, wavelength, and vertical propagation direction. J Atmos Sci 62:125-142

Watanabe S, Kawatani Y, Tomikawa Y, Miyazaki K, Takahashi M, Sato K (2008) General aspects of a t2131256 middle atmosphere general circulation model. J Geophys Res 113:12110. doi:10.1029/2008JD010026

Xu X, Manson AH, Meek CE, Riggin DM, Jacobi C, Drummond JR (2012) Mesospheric wind diurnal tides within the canadian middle atmosphere model data assimilation system. J Atmos Solar-Terr Phys 74(0):24-43

Yamazaki Y, Richmond AD, Liu H, Yumoto K, Tanaka Y (2012) Sq current system during stratospheric sudden warming events in 2006 and 2009. J Geophys Res 117(A12):12313. doi:10.1029/2012JA018116

Yoshikawa M, Miyahara S (2005) Excitations of nonmigrating diurnal tides in the mesosphere and lower thermosphere simulated by the Kyushu-GCM. Adv Space Res 35:1918-1924

Yue J, Wang W, Richmond AD, Liu H-L (2012) Quasi-two-day wave coupling of the mesosphere and lower thermosphere-ionosphere in the TIME-GCM: two-day oscillations in the ionosphere. J Geophys Res 117(A7):07305. doi:10.1029/2012JA017815

Zhang X, Forbes JM, Hagan ME (2010a) Longitudinal variation of tides in the MLT region: 1. Tides driven by tropospheric net radiative heating. J Geophys Res 115:06316. doi:10.1029/2009JA014897

Zhang, X, Forbes JM, Hagan ME (2010b) Longitudinal variation of tides in the MLT region: 2. Relative effects of solar radiative and latent heating. J Geophys Res 115(A6):06317

Zhang Y, Xiong J, Liu L, Wan W (2012) A global morphology of gravity wave activity in the stratosphere revealed by the 8-year SABER/TIMED data. J Geophys Res 117:21101. doi:10.1029/2012jd017676

\section{Submit your manuscript to a SpringerOpen ${ }^{\odot}$ journal and benefit from:}

- Convenient online submission

Rigorous peer review

- Immediate publication on acceptance

- Open access: articles freely available online

- High visibility within the field

- Retaining the copyright to your article

Submit your next manuscript at $>$ springeropen.com 